\title{
Induction of apoptosis by ethanol extract of Prunus mume in U937 human leukemia cells through activation of caspases
}

\author{
CHEOL PARK $^{1}$, CHENG-YUN JIN ${ }^{1,2}$, GI-YOUNG KIM ${ }^{3}$, YONG KEE JEONG ${ }^{4}$, \\ WUN-JAE KIM ${ }^{5}$ and YUNG HYUN CHOI ${ }^{1,2,6}$
}

\begin{abstract}
${ }^{1}$ Department of Biochemistry and Research Institute of Oriental Medicine, Dongeui University College of Oriental Medicine, Busan 614-052; ${ }^{2}$ Department of Biomaterial Control (BK21 Program), Dongeui University Graduate School, Busan 614-714; ${ }^{3}$ Laboratory of Immunobiology, Department of Marine Life Sciences, Jeju National University,

Jeju 690-756; ${ }^{4}$ Department of Medical Bioscience, Graduate School and Department of Biotechnology, College of Natural Resources and Life Science, Dong-A University, Busan 604-714; ${ }^{5}$ Department of Urology,

Chungbuk National University College of Medicine, Cheongju, Chungbuk 361-763; ${ }^{6}$ Blue-Bio Industry

Regional Innovation Center, Dongeui University, Busan 614-714, Republic of Korea
\end{abstract}

Received March 3, 2011; Accepted May 2, 2011

DOI: $10.3892 /$ or.2011.1363

\begin{abstract}
Prunus mume (P. mume), a traditional drug and health food in Korea, Japan and China, possesses various pharmacological activities that include a potential source of free radical scavenging, anti-viral, anti-microbial, antiinflammatory and anti-cancer activities. However, the cellular and molecular mechanisms of apoptosis induction by $P$. mume in human cancer cells are poorly understood. In the present study, we conducted an investigation of the pro-apoptotic effects of an ethanol extract of P. mume (EEPM) in U937 human leukemia cells. Exposure to EEPM was found to result in a concentration-dependent growth inhibition by induction of apoptosis. Induction of apoptotic cell death of U937 cells by EEPM showed a correlation with the down-regulation of members of the inhibitor of apoptosis protein (IAP) family, including X-linked inhibitor of apoptosis protein (XIAP) and survivin, and anti-apoptotic Bcl-2, up-regulation of FasL, and cleavage of Bic. EEPM treatment induced proteolytic activation of caspase-3, -8 and -9 , and degradation of caspase-3 substrate proteins, including poly(ADP-ribose) polymerase (PARP) and $\beta$-catenin. In addition, apoptotic cell death induced by EEPM was significantly inhibited by z-DEVD-fmk, a caspase-3-specific inhibitor, which demonstrated the important role played by caspase- 3 in the process. Taken together, these findings suggest that EEPM may be a potential chemotherapeutic agent for use in the control of
\end{abstract}

Correspondence to: Dr Yung Hyun Choi, Department of Biochemistry, Dongeui University College of Oriental Medicine, Busan 614-052, Republic of Korea

E-mail: choiyh@deu.ac.kr

Key words: Prunus mume, U937 cells, apoptosis, caspase-3 human leukemia U937 cells and that further studies are needed for the identification of the active compounds.

\section{Introduction}

Leukemia, a malignant hematopoietic tumor, is a cancer of the blood or bone marrow characterized by abnormal proliferation of white blood cells; it ranks sixth among a number of human tumors worldwide (1). Leukemias are classified into two subtypes: acute lymphocytic leukemia originating from lymphocytes in the bone marrow and myelogenous leukemia originating from granulocytes or monocytes $(2,3)$. Treatment of leukemia is difficult, and the probability of recurrence is high due to chemoresistance. To overcome these defects, novel therapeutic strategies are needed to be developed for more effective treatment of this serious disease.

Apoptosis, an active process of programmed cell death, is characterized by DNA fragmentation, cell shrinkage, nuclear condensation, cell surface expression of phosphatidylserine and membrane blebbing. In general, apoptosis is mediated through two major pathways: the extrinsic (death receptormediated) and intrinsic (mitochondrial-mediated) pathways. The extrinsic pathway is initiated at the plasma membrane by interaction between ligands and death receptors, such as Fas and Fas ligand (FasL), as well as tumor necrosis factor-related apoptosis-inducing ligand (TRAIL) and death receptors (DRs), and, subsequently, activation of caspase-8. Caspase-8, an initiator caspase, can directly activate downstream effector caspases, including caspase-3 $(4,5)$. In some cells, caspase- 8 also mediates the intrinsic pathway via cleavage of the proapoptotic Bid protein (6,7). The intrinsic pathway is triggered by mitochondrial dysfunction by a broad range of physical and chemical stimuli (8-10). Mitochondrial dysfunction induces activation of caspase-9 and subsequently activates effector caspases, such as caspase-3 (11). Following activation of caspase-3, several specific substrates, including poly(ADPribose) polymerase (PARP) and $\beta$-catenin, are cleaved, 
eventually leading to apoptosis $(12,13)$. In particular, caspases, a family of cysteine-containing aspartate-specific proteases, are known to be regulated by various molecules, including members of the Bcl-2 family and inhibitors of the apoptosis protein (IAP) family. Bcl-2 family proteins are involved in control of the process of apoptosis by interactions between pro-apoptotic (such as Bax and Bad) and anti-apoptotic (such as Bcl-2 and $\mathrm{Bcl}-\mathrm{X}_{\mathrm{L}}$ ) members, particularly those of the intrinsic pathway with mitochondrial dysfunction. Cellular proteins of the IAP family (including XIAP, cIAP-1, cIAP-2, and survivin) have been identified in insect cells infected by the baculovirus and have been shown to regulate apoptosis in vertebrates and Drosophila melanogaster $(14,15)$. They specifically inhibit the activity of caspase- 3 and -9 , while they do not inhibit caspase-8. In the intrinsic pathway, members of the IAP family bind directly to the principal caspase, such as procaspase-3 and -9 , and inhibit apoptosis induced by Bcl-2 family proteins (16-18). According to recent studies, many chemopreventive and/or chemotherapeutic agents can cause cell death via induction of apoptosis. Therefore, induction of apoptotic cell death is an important mechanism in the anticancer properties of many drugs (19).

Prunus mume, a member of the Rosaceae family, is widely distributed in Korea, Japan, and China, and has long been used as a traditional drug and health food. Previous reports have suggested that $P$. mume exerts a wide array of pharmacological and biological activities, such as potential sources of free radical scavengers, inhibition of influenza A virus, inhibition of the motility of Helicobacter pylori, improvement of blood fluidity, and inhibition of pro-inflammatory mediators (20-25). In addition, $P$. mume has been known to exert anticancer activities in several types of human cancer cells (26-28). However, cellular and molecular mechanisms underlying the anti-cancer effects of P. mume are not yet fully understood.

In the present study, we conducted an investigation of the effect of apoptosis by an ethanol extract of P. mume (EEPM) in human leukemia U937 cells. We found that EEPM-induced apoptosis was accompanied by modulation of the Fas/Fas ligand (FasL) system, Bcl-2 family and IAP family members, and proteolytic activation of caspases. In addition, blockade of caspase- 3 activation reduced EEPM-induced apoptosis in U937 cells.

\section{Materials and methods}

Reagents and antibodies. Fetal bovine serum (FBS), RPMI1640, penicillin, streptomycin, and trypsin-EDTA were purchased from Gibco-BRL (Gaithersburg, MD, USA). 4,6-Diamidino-2-phenylindole (DAPI), propidium iodide (PI), paraformaldehyde, 3-(4,5-dimethyl-2-thiazolyl)-2,5-diphenyl$2 \mathrm{H}$-tetrazolium bromide (MTT), RNase A, and proteinase $\mathrm{K}$ were purchased from Sigma Chemicals (St. Louis, MO, USA). An enhanced chemiluminescence kit (ECL) was purchased from Amersham Corp. (Arlington Heights, IL, USA). Caspase activity assay kits were obtained from R\&D Systems (Minneapolis, MN, USA), and the caspase-3-specific inhibitor, z-DEVD-fmk, was obtained from Calbiochem (San Diego, CA, USA). DNA ladder size markers were purchased from Invitrogen (Carlsbad, CA, USA). Antibodies of TRAIL, DR4, DR5, Fas, FasL, XIAP, cIAP-1, cIAP-2, survivin, Bcl-2,
Bcl-X $\mathrm{X}_{\mathrm{L}}, \mathrm{Bax}, \mathrm{Bad}, \mathrm{Bid}$, caspase-3, caspase-8, caspase-9, PARP, $\beta$-catenin, and actin were purchased from Santa Cruz Biotechnology (Santa Cruz, CA, USA). Horseradish peroxidase (HRP)-conjugated anti-mouse and anti-rabbit secondary antibodies were purchased from Amersham Corp. Other chemicals not specifically cited here were purchased from Sigma.

Cell culture and preparation of EEPM. Human leukemia U937 cells were obtained from the American Type Culture Collection (Rockville, MD, USA). Cells were cultured in RPMI-1640 medium supplemented with $10 \%$ heat-inactivated FBS, $2 \mathrm{mM}$ glutamine, $100 \mathrm{U} / \mathrm{ml}$ penicillin, and $100 \mu \mathrm{g} / \mathrm{ml}$ streptomycin in a humidified environment with $5 \% \mathrm{CO}_{2}$ at $37^{\circ} \mathrm{C}$. For preparation of the ethanol extract of $P$. mume (EEPM), freeze-dried fruits of $P$. mume were extracted with ethanol (100 g per 1 liter) at $60^{\circ} \mathrm{C}$ for 3 days using a blender. The extract was centrifuged at 3,000 rpm for $20 \mathrm{~min}$, and the supernatants were then collected and immediately filtered through a Whatman (Maidstone, UK) filter (pore size, $0.22 \mu \mathrm{m}$ ). The filtrate was lyophilized and stored at $-70^{\circ} \mathrm{C}$. The yield $(\mathrm{w} / \mathrm{w})$ of the extract was $\sim 5.0 \%$. The powder was dissolved to a $100 \mathrm{mg} / \mathrm{ml}$ concentration with dimethyl sulfoxide (DMSO), and the stock solution was then diluted with medium to the desired concentration prior to use.

Cell proliferation assay. Cells were seeded into 6-well plates at $1 \times 10^{5}$ cells $/ \mathrm{ml}$ and incubated for $48 \mathrm{~h}$ at $37^{\circ} \mathrm{C}$ in the absence or presence of variable concentrations of EEPM. Following incubation, cells were washed with phosphate-buffered saline (PBS), trypsinized, and manually counted with a hemocytometer through exclusion of trypan blue. For the morphological study, cells were treated with EEPM for $48 \mathrm{~h}$ and then photographed directly using an inverted microscope (Carl Zeiss, Germany).

Cell viability assay. A cell viability assay was performed using MTT assay. For the MTT assay, cells were treated with EEPM for $48 \mathrm{~h}$. After treatments, $0.5 \mathrm{mg} / \mathrm{ml}$ MTT solution was added, followed by incubation for $2 \mathrm{~h}$ at $37^{\circ} \mathrm{C}$ in the dark. Absorbance of each well was measured at $540 \mathrm{~nm}$ with an enzyme-linked immunosorbent assay (ELISA) reader (Molecular Devices, Sunnyvale, CA, USA).

Nuclear staining with DAPI. For evidence of apoptosis, morphological changes of nuclei were visualized following DNA staining by the fluorescent dye DAPI. Cells were seeded at $1 \times 10^{5}$ cells $/ \mathrm{ml}$ in 6 -well plates and incubated with EEPM. After incubation, cells were fixed with $3.7 \%$ paraformaldehyde for $20 \mathrm{~min}$ at room temperature and washed with PBS. Cells were then stained with $2.5 \mu \mathrm{g} / \mathrm{ml}$ DAPI solution for $10 \mathrm{~min}$ at room temperature. Cells were then washed twice with PBS, and stained nuclei were observed using fluorescence microscopy (Carl Zeiss).

DNA fragmentation assay. Cells were lysed on ice in a buffer containing $10 \mathrm{mM}$ Tris- $\mathrm{HCl}(\mathrm{pH}$ 7.4), $150 \mathrm{mM} \mathrm{NaCl}, 5 \mathrm{mM}$ EDTA, and $0.5 \%$ Triton $\mathrm{X}-100$ for $30 \mathrm{~min}$ at room temperature. Lysates were vortexed and cleared by centrifugation for $20 \mathrm{~min}$ at $14,000 \mathrm{rpm}$, followed by treatment of the supernatant 
samples with proteinase $\mathrm{K}$ for $3 \mathrm{~h}$ at $50^{\circ} \mathrm{C}$. Fragmented DNA in the supernatant was extracted using an equal volume of neutral phenol:chloroform:isoamyl alcohol (25:24:1, v/v/v). The upper aqueous layer was supplemented with $5 \mathrm{M} \mathrm{NaCl}$ and isopropanol, and incubated for $6 \mathrm{~h}$ at $-20^{\circ} \mathrm{C}$. Following centrifugation for $15 \mathrm{~min}$ at $14,000 \mathrm{rpm}$, DNA pellets were air-dried and dissolved in $20 \mu \mathrm{l}$ of TE buffer $(10 \mathrm{mM}$ Tris- $\mathrm{HCl}$ and $1 \mathrm{mM}$ EDTA) with $300 \mu \mathrm{g} / \mathrm{ml}$ RNase. DNA samples were finally separated on $1.6 \%$ agarose gels and observed using an ultraviolet light source after staining with ethidium bromide (EtBr, Sigma) (29).

DNA flow cytometric analysis. After treatment with EEPM, cells were harvested, washed twice with ice-cold PBS, and fixed with $75 \%$ ethanol at $4^{\circ} \mathrm{C}$ for $30 \mathrm{~min}$, and the DNA content of the cells was stained using a DNA staining kit (CycleTEST PLUS Kit, Becton-Dickinson, San Jose, CA, USA) with PI. DNA content at the sub-G1 phases was then determined by FACSCalibur (Becton-Dickinson) and analyzed by CellQuest software (Becton-Dickinson).

Protein extraction and Western blot analysis. Cells were collected with ice-cold PBS and immediately lysed with lysis buffer ( $20 \mathrm{mM}$ sucrose, $1 \mathrm{mM}$ EDTA, $20 \mu \mathrm{M}$ Tris-Cl, pH 7.2, $1 \mathrm{mM}$ DTT, $10 \mathrm{mM} \mathrm{KCl}, 1.5 \mathrm{mM} \mathrm{MgCl}{ }_{2}, 5 \mu \mathrm{g} / \mathrm{ml}$ pepstatin A, $10 \mu \mathrm{g} / \mathrm{ml}$ leupeptin, and $2 \mu \mathrm{g} / \mathrm{ml}$ aprotinin) containing protease inhibitors. A Bio-Rad protein assay (Bio-Rad, Hercules, CA, USA) was used according to the manufacturer's instructions for determination of the protein concentrations. After normalization, an equal amount of protein was subjected to electrophoresis on sodium dodecyl sulfate (SDS)-polyacrylamide gels and then transferred to a nitrocellulose membrane (Schleicher \& Schuell, Keene, NH, USA) by electroblotting. The membrane was blocked with 5\% skim milk and incubated with the primary antibodies and HRP-conjugated anti-mouse and anti-rabbit secondary antibodies. An enhanced ECL detection system was used for visualization of target proteins (30).

In vitro caspase activity assay. A colorimetric assay using caspase- $3,-8$, and -9 activation kits was used according to the manufacturer's protocol for determination of caspase activity. Briefly, harvested cell pellets were lysed in a lysis buffer for $30 \mathrm{~min}$ at room temperature and centrifuged at $14,000 \mathrm{rpm}$ for $20 \mathrm{~min}$. Supernatants were collected and immediately measured for protein concentration. Equal amounts of protein $(150 \mu \mathrm{g}$ per $50 \mu \mathrm{l})$ were incubated with $50 \mu \mathrm{l}$ of a reaction buffer and $5 \mu 1$ of colorimetric tetrapeptides, Asp-Glu-Val-Asp (DEVD)-p-nitroaniline (pNA) for caspase-3, Ile-Glu-Thr-Asp (IETD)-pNA for caspase-8, and Leu-Glu-His-Asp (LEHD)-pNA for caspase-9, respectively, at $37^{\circ} \mathrm{C}$ for $2 \mathrm{~h}$ in the dark. Caspase activity was determined by measurement of changes in absorbance at a wavelength of $405 \mathrm{~nm}$ using the ELISA reader (31).

Statistical analysis. Data are expressed as the mean \pm SD. One-way ANOVA followed by a Fisher's exact test was used in performance of statistical comparison. Significant differences between groups were determined using an unpaired Student's t-test. A p-value $<0.05$ was considered significant.
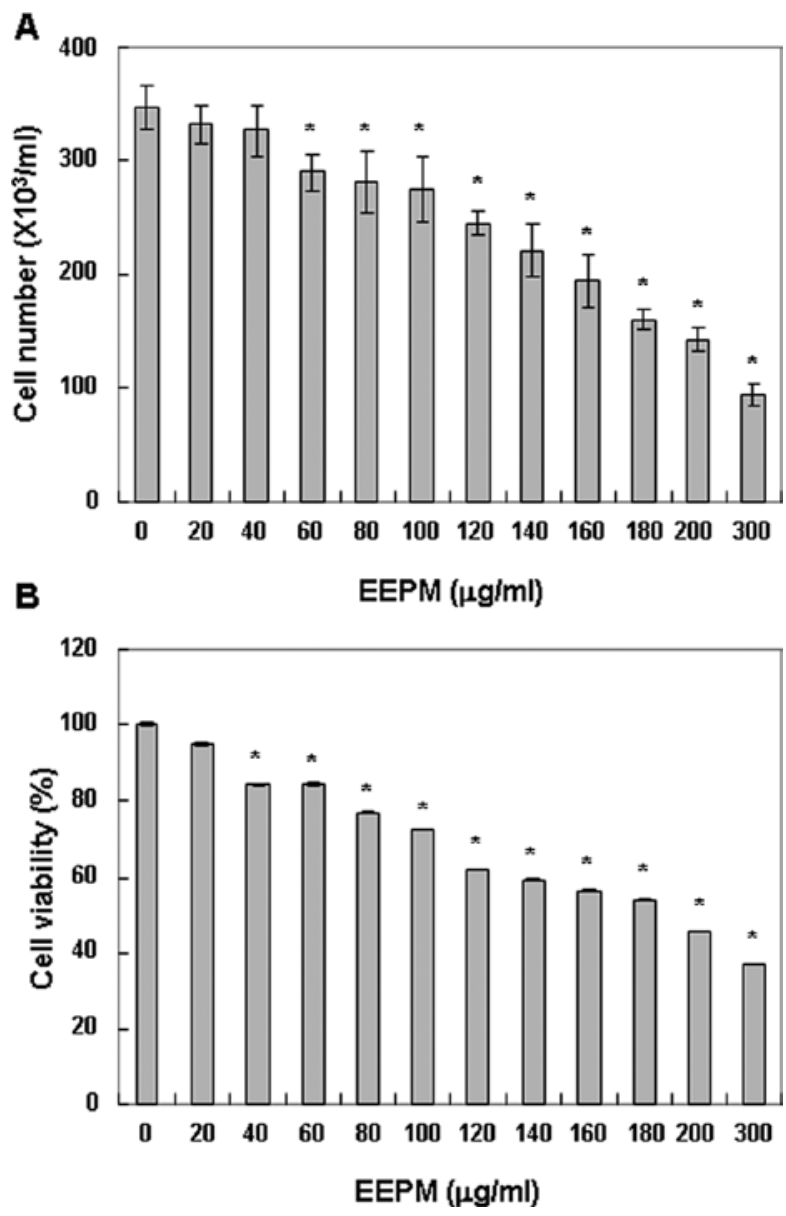

Figure 1. Inhibition of cell proliferation and viability by an ethanol extract of P. mume (EEPM) in human leukemia U937 cells. Cells were seeded into 6 -well plates at $1 \times 10^{5}$ cells $/ \mathrm{ml}$ and treated with the indicated concentration of EEPM for $48 \mathrm{~h}$. Cell number (A) and viability (B) were determined by hemocytometer counts of trypan blue exclusion method and MTT assay, respectively. Results are expressed as the percentage of the vehicle-treated control \pm SD of three separate experiments. A Student's t-test ( $\mathrm{p}<<0.05$ vs. untreated control) was used for determination of significance.

\section{Results}

EEPM inhibits proliferation and cell viability in U937 cells. To investigate the potential effects of EEPM on cell growth, U937 cells were treated with various concentrations of EEPM for $48 \mathrm{~h}$, and the cell number and viability were then measured by the tryphan blue exclusion method and MTT assay, respectively. As shown in Fig. 1, EEPM induced significant inhibition of proliferation and viability of U937 cells in a concentration-dependent manner. In addition, visual inspection by inverted microscopy revealed that treatment with EEPM resulted in numerous morphological changes (Fig. 2A).

EEPM induces apoptosis in U937 cells. To ascertain whether growth inhibition by EEPM is associated with apoptosis, we examined the apoptotic features by measurement of chromatin condensation of nuclei, DNA fragmentation, and the number of cells in the sub-G1 phase. Treatment with EEPM resulted in the observation of a significant number of cells with chromatin condensation and formation of apoptotic bodies in a concentration-dependent manner, whereas these features were not 


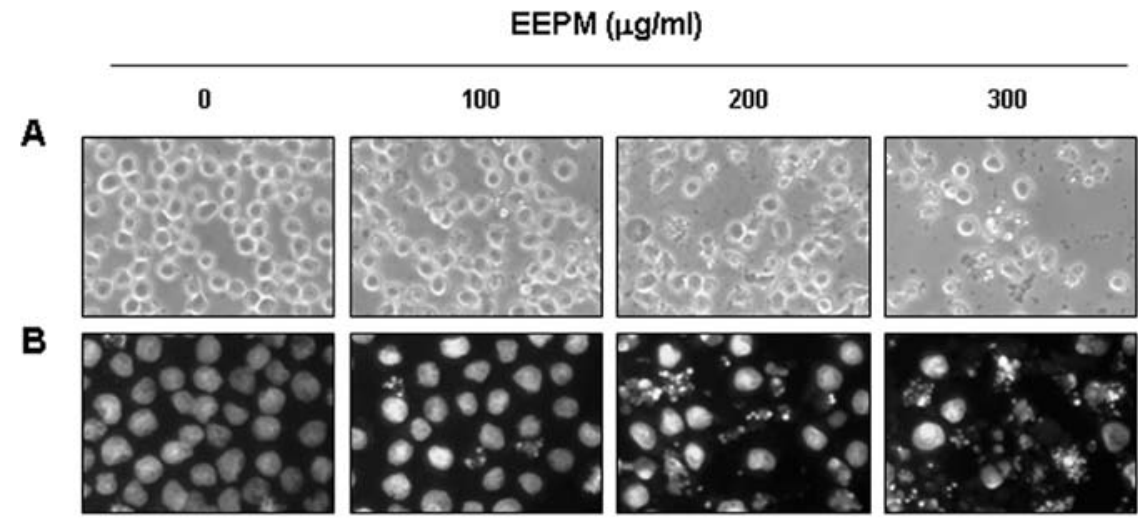

C

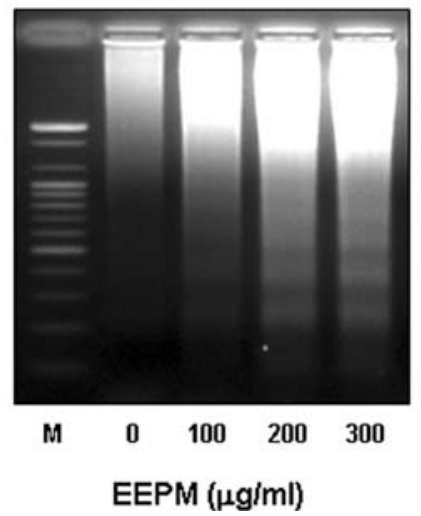

D

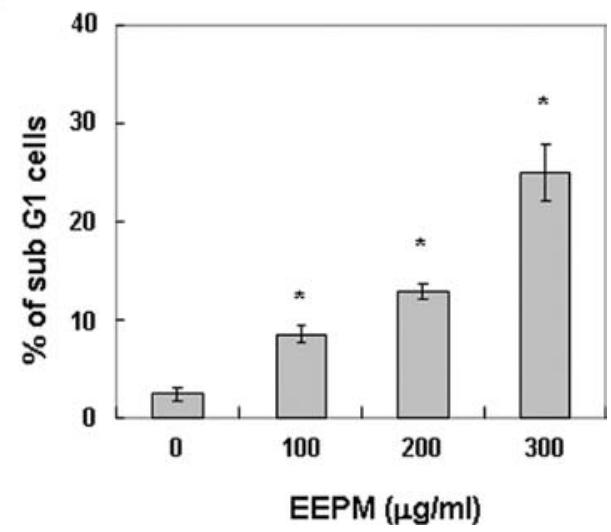

Figure 2. Induction of apoptosis by EEPM treatment in U937 cells. Cells were seeded into 6-well plates at $1 \times 10^{5}$ cells/ml and treated with the indicated concentrations of EEPM for 48 h. (A) Cell morphology was visualized by light microscopy. Magnification, x200. (B) Nuclei stained with DAPI solution were photographed with a fluorescence microscope using a blue filter. Magnification, x400. (C) For analysis of DNA fragmentation, genomic DNA was extracted, electrophoresed in a 1.6\% agarose gel, and visualized by EtBr staining. (D) To quantify the degree of apoptosis induced by EEPM, cells were evaluated for sub-G1 DNA content, which represents the cell fraction undergoing apoptotic DNA degradation, using a flow cytometer. Results are expressed as a percentage of the vehicle-treated control \pm SD of three separate of cells experiments. The Student's t-test ( ${ }^{*} \mathrm{p}<0.05$ vs. untreated control) was used for determination of significance.

observed in the control cells (Fig. 2B). As shown in Fig. 2C, treatment with EEPM induced a progressive accumulation of fragmented DNA, which appeared as a typical ladder pattern of DNA fragmentation due to inter-nucleosomal cleavage associated with apoptosis, in a concentration-dependent manner. In addition, the degree of apoptosis was determined by analysis of the amount of sub-G1 DNA content in the U937 cells treated with EEPM using flow cytometry. As shown in Fig. 2D, treatment with EEPM resulted in an increased accumulation of cells with sub-G1 DNA content. Taken together, these results revealed a good correlation between the extent of apoptosis and inhibition of growth in U937 cells.

Effects of EEPM on the expression of apoptosis-related proteins. In order to determine which apoptosis pathway contributes to EEPM-induced apoptosis, the death receptor and corresponding pro-apoptotic ligands were first examined using Western blot analysis. Results showed that EEPM treatment resulted in a concentration-dependent increase in the level of FasL. However, levels of TRAIL, DR4, DR5, and Fas expression were relatively unchanged in response to EEPM treatment (Fig. 3A). Next, we examined the effects of EEPM on levels of the Bcl-2 family proteins. As shown in Fig. 3B, levels of anti-apoptotic Bcl-2 expression were significantly inhibited in response to EEPM treatment, and the pro-apoptotic protein Bid, a BH3-only pro-apoptotic member of the Bcl-2 family, was truncated in a concentrationdependent manner, whereas the levels of anti-apoptotic $\mathrm{Bcl}-\mathrm{X}_{\mathrm{L}}$, and pro-apoptotic Bax and Bad remained virtually unchanged in response to EEPM treatment. Under the same conditions, expression levels of the IAP family proteins were also examined. Fig. 3C shows that EEPM treatment resulted in a concentration-dependent decrease in the expression levels of the XIAP and survivin proteins, but not cIAP-1 and cIAP-2.

EEPM induces activation of caspases and cleavage of caspase-3 substrate proteins. According to recent studies, caspases are very important regulators of the apoptotic pathway. Therefore, we examined the expression levels and activities of caspase-3, -8, and -9 during EEPM-induced apoptosis by Western blot analysis and the in vitro caspase activity assay. Results showed that EEPM treatment resulted in cleavage and/or down-regulation of pro-caspase-3, -8, and -9 proteins in a concentration-dependent manner (Fig. 4A). To further quantify the proteolytic activation of the caspases, we determined that lysates equalized for protein were obtained from cells treated with EEPM using DEVD-pNa, IETD-pNA, and LEHD-pNA as substrates for caspase-3, -8, and -9, 


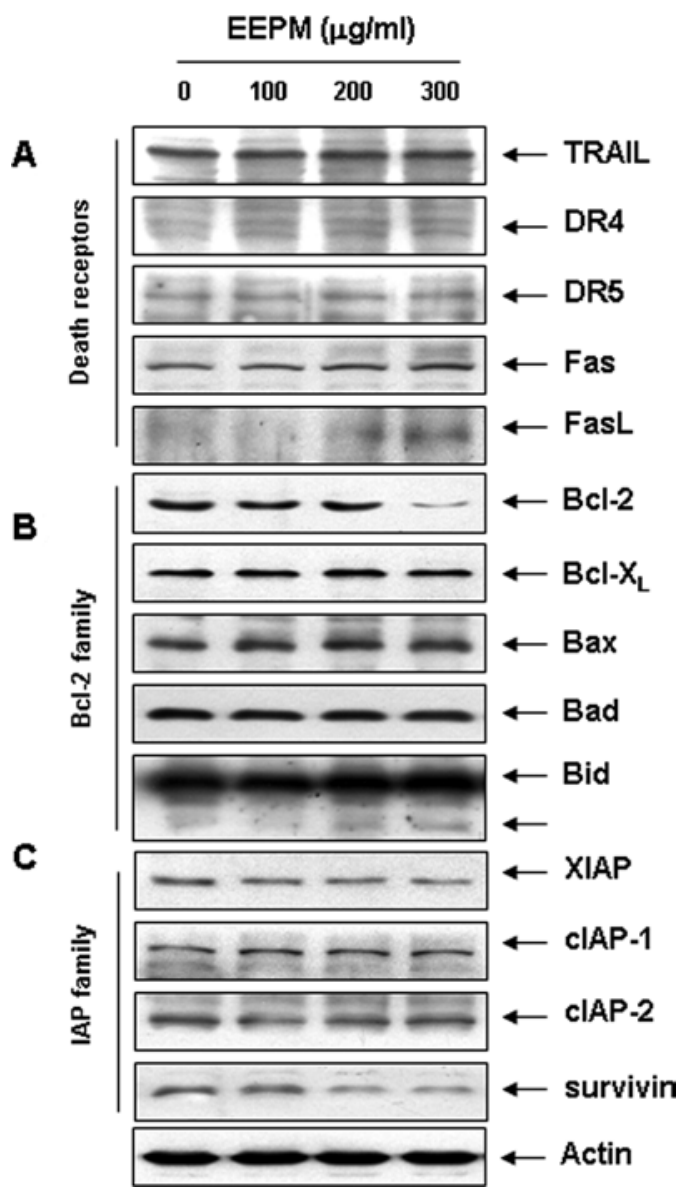

Figure 3. Effects of EEPM on levels of apoptosis-related proteins in U937 cells. Cells were treated with the indicated concentration of EEPM for $48 \mathrm{~h}$. Cells were lysed, and then equal amounts of cell lysates $(30 \mu \mathrm{g})$ were separated on SDS-polyacrylamide gels and transferred to nitrocellulose membranes. Membranes were probed with the indicated antibodies, and the proteins were visualized using an ECL detection system. Actin was used as an internal control.

respectively. As shown in Fig. 4B, treatment with EEPM resulted in a marked increase of the activity in caspase- $3,-8$, and -9 in a concentration-dependent manner. In addition, EEPM treatment led to progressive proteolytic cleavage and/ or down-regulation of PARP and $\beta$-catenin proteins, endogeneous caspase-3 substrates (Fig. 4A).

Inhibition of EEPM-induced apoptosis by caspase-3 inhibitor. To further confirm the involvement of EEPM-induced activation of caspase-3 in EEPM-induced apoptotic cell death, U937 cells were pre-treated with or without z-DEVD-fmk $(50 \mu \mathrm{M})$, a caspase-3-specific inhibitor, for $1 \mathrm{~h}$, followed by treatment with EEPM for $48 \mathrm{~h}$, respectively. As shown in Fig. 5A, treatment with z-DEVD-fmk resulted in significant prevention of the appearance of cells with apoptotic features, such as chromatin condensation and formation of apoptotic bodies, indicating that EEPM-induced apoptotic cell death was mediated through caspase-3 activation. Similarly, pre-treatment with z-DEVD-fmk induced restoration of cell viability and attenuation of the progressive accumulation of fragmented DNA (Fig. 5B and C). These results provide evidence of EEPM-


Figure 4. Activation of caspases and degradation of the PARP and $\beta$-catenin protein by EEPM treatment in U937 cells. Cells were treated with the indicated concentration of EEPM for 48 h. (A) Cells were lysed, and then equal amounts of cell lysates $(30 \mu \mathrm{g})$ were separated on SDS-polyacrylamide gels and transferred to nitrocellulose membranes. Membranes were probed with the indicated antibodies. An ECL detection system was used for visualization of proteins. Actin was used as an internal control. (B) Cells grown under the same conditions as A were collected and lysed. Aliquots were incubated with DEVD-pNA, IETD-pNA, and LEHD-pNA for caspase-3, -8, and -9, individually, at $37^{\circ} \mathrm{C}$ for $1 \mathrm{~h}$. Released fluorescence products were measured. Data represent the mean of three independent experiments. A Student's t-test $\left({ }^{*} \mathrm{p}<0.01\right)$ was used for analysis of statistical significance of the results.

induced apoptotic cell death in association with activation of caspase-3 in U937 cells.

\section{Discussion}

P. mume is a fruit tree belonging to the Rosaceae family and is widely cultivated in East Asian countries. From ancient times, various parts of $P$. mume have been used as a health food and a medicinal agent for the treatment of fever, cough, and intestinal disorders. In addition, recent studies have reported that $P$. mume possesses various pharmacological activities, including inhibition of influenza A virus and motility of Helicobacter pylori, potential sources of free radical scavengers, improvement of blood fluidity, anti-inflammation, and anti-cancer action (21-28). However, the cellular and molecular mechanisms responsible for the apoptotic effects of P. mume have not yet been determined in human cancer cells. In the present study, using a human leukemia U937 cell line, 
A

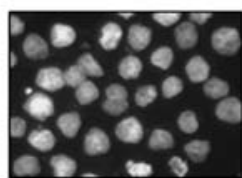

$-$

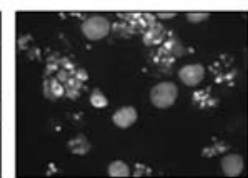

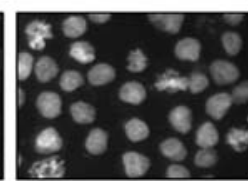

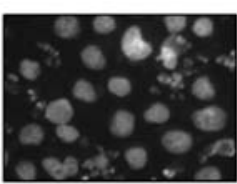

$+\quad$ z-DEVD-fmk $50 \mu \mathrm{M}$

$+\quad$ EEPM $300 \mu \mathrm{g} / \mathrm{ml}$

B

C


Figure 5. Inhibition of EEPM-induced apoptosis by the caspase-3 inhibitor in U937 cells. U937 cells were pre-treated for $1 \mathrm{~h}$ with or without z-DEVD-fmk, and then treated with EEPM for an additional $48 \mathrm{~h}$. (A) Cells were stained with DAPI for 10 min and photographed with a fluorescence microscope using a blue filter. Magnification, x400. (B) Growth inhibition was measured by the metabolic-dye-based MTT assay. Results are expressed as the percentage of the vehicle-treated control $\pm \mathrm{SD}$ of three separate experiments. A Student's t-test ( ${ }^{*} \mathrm{p}<0.05$ vs. untreated control) was used for determination of significance. (C) Cells grown under the same conditions as A were collected, and the genomic DNA was extracted. DNA fragmentation was analyzed by electrophoresis on a $1.6 \%$ agarose gel containing EtBr.

we demonstrated the inhibition of cell growth and viability by EEPM, as well as an alteration in cell morphology in a concentration-dependent manner (Figs. 1 and 2A). To further confirm that EEPM-induced anti-proliferative effects are related to the induction of apoptosis, induction of apoptosis by EEPM was confirmed by measurement of chromatin condensation of nuclei, DNA fragmentation, and induction of the sub-G1 phase (Fig. 2B-D).

Regulation of apoptosis is critical for maintenance of tissue development and homeostasis (32). Dysregulated apoptosis induces a number of pathological conditions, including cancer. Therefore, induction of apoptosis is an important target for cancer therapy. Apoptosis is mediated through activation of either an extrinsic (death receptor-mediated) or intrinsic (mitochondrial-mediated) pathway, both regulated by caspases, death receptors and the $\mathrm{Bcl}-2$ family. The extrinsic pathway is activated by the binding of death receptors to their ligands. Binding of death receptors and their ligands induces activation of caspase- 8 and triggers the caspase cascade downstream, including caspase-3 $(4,5,33,34)$. The intrinsic pathway is triggered by cell stressors (including ultraviolet and $\gamma$-irradiation, heat and DNA damage) and many chemotherapeutic agents, resulting in induction of mitochondrial dysfunction. Members of the Bcl-2 family are the major genes involved in the regulation of the intrinsic pathway. In mammals, anti-apoptotic members of this family include $\mathrm{Bcl}-2$ and $\mathrm{Bcl}-\mathrm{X}_{\mathrm{L}}$, and proapoptotic members include Bax, Bak, Bad, Bim and Bid. The balance between anti-apoptotic and pro-apoptotic members decides the fate of the cell through mitochondrial dysfunction $(8,9)$. In addition, members of the IAP family have been reported to exert their anti-apoptotic effects due to their function as direct inhibitors of activated caspases. Therefore, down-regulation of IAPs relieves the triggering block of pro-apoptotic signaling and the execution caspases, thus activating cell death $(17,35)$. In the present study, we demonstrated that EEPM-induced apoptosis is associated with an increase in FasL, a decrease in Bcl-2, and cleavage of Bid. In addition, expression levels of the XIAP and survivin proteins were decreased by EEPM in a concentration-dependent manner (Fig. 3).

Caspases, a family of cysteine-containing aspartatespecific proteases, are known to play key roles during apoptosis and lead to the initiation and execution of apoptosis. Activation of initiator caspases, such as caspase- 8 and -9 , resulted in downstream activation of effector caspases, such as caspase-3, -6 , and -7 (4,5). In particular, activation of capase-3 is responsible for the proteolytic degradation of many key proteins, including PARP and $\beta$-catenin, finally leading to apoptosis $(13,36)$. In the present study, we demonstrated that treatment with EEPM induced activation of capase-3, -8, and -9, and concomitant proteolytic degradation and/or down-regulation of PARP and $\beta$-catenin proteins (Fig. 4). In addition, pre-treatment with the caspase-3-specific inhibitor, z-DEVD-fmk, prevented chromatin condensation and DNA fragmentation, and restored cell viability by EEPM (Fig. 5). The present data demonstrated that EEPM induced an increase in the levels of FasL and the enzymatic activity of extrinsic and intrinsic caspase cascades, such as caspase- 8 and -9 , which was associated with increased levels of truncated Bid expression. In addition, caspase- 3 was activated and PARP and $\beta$-catenin proteins were then progressively cleaved in the EEPM-treated U937 cells.

In summary, the results of this study demonstrate that EEPM triggers the apoptosis of human leukemic U937 cells 
through activation of the intrinsic caspase pathway along with the death receptor-mediated extrinsic pathway, and that caspase-3 is the key molecule responsible for mediation of EEPM-induced apoptosis. However, it is still unclear whether $P$. mume can induce apoptosis through other pathways, and further studies are needed for the identification of the active compounds. Results of this study provide new information on possible mechanisms for the anti-cancer activity of $P$. mume.

\section{Acknowledgements}

This study was supported by the Basic Science Research Program through the National Research Foundation of Korea, funded by the Ministry of Education, Science and Technology (2010-0001730), and Technology Development Program for Agriculture and Forestry (610003-03-1-SU000), Ministry for Food, Agriculture, Forestry and Fisheries.

\section{References}

1. Chang H, Lin H, Yi L, Zhu J, Zhou Y, Mi M and Zhang Q 3,6-Dihydroxyflavone induces apoptosis in leukemia HL-60 cells via reactive oxygen species-mediated p38 MAPK/JNK pathway. Eur J Pharmacol 648: 31-38, 2010.

2. Gilliland DG, Jordan CT and Felix CA: The molecular basis of leukemia. Hematology Am Soc Hematol Educ Program 80-97, 2004.

3. Abramson $\mathrm{N}$ and Melton B: Leukocytosis: basics of clinical assessment. Am Fam Physician 62: 2053-2060, 2000.

4. Scaffidi C, Fulda S, Srinivasan A, Friesen C, Li F, Tomaselli KJ, Debatin KM, Krammer PH and Peter ME: Two CD95 (APO-1/ Fas) signaling pathways. EMBO J 17: 1675-1687, 1998.

5. Lawen A: Apoptosis - an introduction. Bioessays 25: 888-896, 2003.

6. Li H, Zhu H, Xu CJ and Yuan J: Cleavage of BID by caspase-8 mediates the mitochondrial damage in the Fas pathway of apoptosis. Cell 94: 491-501, 1998.

7. Luo X, Budihardjo I, Zou H, Slaughter C and Wang X: Bid, a bcl-2 interacting protein, mediates cytochrome c release from mitochondria in response to activation of cell surface death receptors. Cell 94: 481-490, 1998.

8. Jin Z and El-Deiry WS: Overview of cell death signaling pathways. Cancer Biol Ther 4: 139-163, 2005.

9. Kroemer G and Reed JC: Mitochondrial control of cell death. Nat Med 6: 513-519, 2000.

10. Liu X, Kim CN, Yang J, Jemmerson R and Wang X: Induction of apoptotic program in cell-free extracts: requirement for dATP and cytochrome c. Cell 86: 147-157, 1996.

11. Li P, Nijhawan D, Budihardjo I, Srinivasula SM, Ahmad M, Alnemri ES and Wang X: Cytochrome $\mathrm{c}$ and dATP-dependent formation of Apaf-1-caspase-9 complex initiates an apoptotic protease cascade. Cell 91: 479-489, 1997.

12. Han SI, Kim YS and Kim TH: Role of apoptotic and necrotic cell death under physiologic conditions. BMB Rep 41: 1-10, 2008.

13. Lazebnik YA, Kaufmann SH, Desnoyers S, Poirier GG and Earnshaw WC: Cleavage of poly(ADP-ribose) polymerase by a proteinase with properties like ICE. Nature 371: 346-347, 1994.

14. Salvesen GS and Duckett CS: IAP proteins: blocking the road to death's door. Nat Rev Mol Cell Biol 3: 401-410, 2002.

15. De Laurenzi V and Melino G: Apoptosis. The little devil of death. Nature 406: 135-136, 2000.

16. Gao Z, Tian Y, Wang J, Yin Q, Wu H, Li YM and Jiang X: A dimeric Smac/Diablo peptide directly relieves caspase-3 inhibition by XIAP. Dynamic and cooperative regulation of XIAP by Smac/Diablo. J Biol Chem 282: 30718-30727, 2007.
17. Deveraux QL and Reed JC: IAP family proteins - suppressors of apoptosis. Genes Dev 13: 239-252, 1999.

18. Deveraux QL, Roy N, Stennicke HR, Van Arsdale T, Zhou Q, Srinivasula SM, Alnemri ES, Salvesen GS and Reed JC: IAPs block apoptotic events induced by caspase- 8 and cytochrome c by direct inhibition of distinct caspases. EMBO J 17: 2215-2223, 1998.

19. Fesik SW: Promoting apoptosis as a strategy for cancer drug discovery. Nat Rev Cancer 5: 876-885, 2005.

20. Yingsakmongkon S, Miyamoto D, Sriwilaijaroen N, Fujita K, Matsumoto K, Jampangern W, Hiramatsu H, Guo CT, Sawada T, Takahashi T, Hidari K, Suzuki T, Ito M, Ito Y and Suzuki Y: In vitro inhibition of human influenza A virus infection by fruitjuice concentrate of Japanese plum (Prunus mume SIEB. et ZUCC). Biol Pharm Bull 31: 511-515, 2008

21. Shi JY, Wu XQ and Zhang Y: A review of the research on utilization and development of Prunus mume. Food Ferment Ind 34: 106-111, 2008.

22. Choi HJ, Kang OH, Park PS, Chae HS, Oh YC, Lee YS, Choi JG, Lee GH, Kweon OH and Kwon DY: Mume fructus water extract inhibits pro-inflammatory mediators in lipopolysaccharidestimulated macrophages. J Med Food 10: 460-466, 2007.

23. Miyazawa M, Utsunomiya H, Inada K, Yamada T, Okuno $\mathrm{Y}$, Tanaka $\mathrm{H}$ and Tatematsu M: Inhibition of Helicobacter pylori motility by $(+)$-Syringaresinol from unripe Japanese apricot. Biol Pham Bull 29: 172-173, 2006.

24. Chuda Y, Ono H, Ohnishi-Kameyama M, Matsumoto K, Nagata T and Kikuchi Y: Mumefural, citric acid derivative improving blood fluidity from fruit-juice concentrate of Japanese apricot (Prunus mume Sieb. et Zucc). J Agric Food Chem 47: 828-831, 1999.

25. Kim BJ, Kim JH, Kim HP and Heo MY: Biological screening of 100 plant extracts for cosmetic use (II): anti-oxidative activity and free radical scavenging activity. Int J Cosmet Sci 9: 299-307, 1997.

26. Mori S, Sawada T, Okada T, Ohsawa T, Adachi M and Keiichi K: New anti-proliferative agent, MK615, from Japanese apricot 'Prunus mume' induces striking autophagy in colon cancer cells in vitro. World J Gastroenterol 13: 6512-6517, 2007

27. Nakagawa A, Sawada T, Okada T, Ohsawa T, Adachi M and Kubota K: New antineoplastic agent, MK615, from UME (a variety of) Japanese apricot inhibits growth of breast cancer cells in vitro. Breast J 13: 44-49, 2007.

28. Okada T, Sawada T, Osawa T, Adachi M and Kubota K: A novel anti-cancer substance, MK615, from ume, a variety of Japanese apricot, inhibits growth of hepatocellular carcinoma cells by suppressing Aurora A kinase activity. Hepatogastroenterology 54: 1770-1774, 2007.

29. Lee JY, Kim JH, Chae G, Lee BK, Ha KS, Kwon YG and Kim YM: Cyclic AMP prolongs graft survival by suppressing apoptosis and inflammatory gene expression in acute cardiac allograft rejection. Exp Mol Med 42: 69-79, 2010.

30. Yue T, Yin J, Li F, Li D and Du M: High glucose induces differentiation and adipogenesis in porcine muscle satellite cells via mTOR. BMB Rep 43: 140-145, 2010

31. Cho SY, Lee JH, Bae HD, Jeong EM, Jang GY, Kim CW, Shin DM, Jeon JH and Kim IG: Transglutaminase 2 inhibits apoptosis induced by calcium-overload through down-regulation of Bax. Exp Mol Med 42: 639-650, 2010.

32. Danial NN and Korsmeyer SJ: Cell death: critical control points. Cell 116: 205-219, 2004

33. Ashkenazi A and Dixit VM: Apoptosis control by death and decoy receptors. Curr Opin Cell Biol 11: 255-260, 1999.

34. Peter ME and Krammer PH: The CD95 (APO-1/Fas) DISC and beyond. Cell Death Differ 10: 26-35, 2003.

35. Roy N, Deveraux QL, Takahashi R, Salvesen GS and Reed JC: The c-IAP-1 and c-IAP-2 proteins are direct inhibitors of specific caspases. EMBO J 16: 6914-6925, 1997.

36. Fukuda K: Apoptosis-associated cleavage of beta-catenin in human colon cancer and rat hepatoma cells. Int J Biochem Cell Biol 31: 519-529, 1999. 